\title{
Amniotic Membrane Grafts in Pediatric Corneal Limbal Dermoids with Conjunctival Eyelashes: A Case Presentation
}

\author{
Larisa Akah Che1, Linda A. Morgan², Donny W. Suh ${ }^{2,3}$ \\ ${ }^{1}$ University of Nebraska Medical Center, Omaha, NE, USA \\ ${ }^{2}$ Children's Hospital \& Medical Center, Omaha, NE, USA \\ ${ }^{3}$ Department of Ophthalmology and Visual Sciences, Truhlsen Eye Institute, University of Nebraska Medical Center, Omaha, NE, USA \\ Email: limorgan@childrensomaha.org
}

How to cite this paper: Che, L.A., Morgan, L.A. and Suh, D.W. (2016) Amniotic Membrane Grafts in Pediatric Corneal Limbal Dermoids with Conjunctival Eyelashes: A Case Presentation. Open Journal of Ophthalmology, 6, 191-197.

http://dx.doi.org/10.4236/ojoph.2016.64027

Received: August 23, 2016

Accepted: October 11, 2016

Published: October 14, 2016

Copyright $\odot 2016$ by authors and Scientific Research Publishing Inc. This work is licensed under the Creative Commons Attribution International License (CC BY 4.0).

http://creativecommons.org/licenses/by/4.0/

\begin{abstract}
Purpose: To report a case of a pediatric corneal limbal dermoid with eyelashes and to describe post-operative changes after excision with reconstruction using amniotic membrane grafting, sutures and fibrinogen-thrombin glue. Case Report: One pediatric patient was identified with a grade II infratemporal corneal-limbal dermoid with conjunctival eyelashes. The dermoid was surgically excised and the cornea reconstructed with amniotic membrane using sutures and fibrinogen/thrombin glue. Preoperative and postoperative measurement of astigmatism, anisometropia and presence of exposure keratopathy were performed.
\end{abstract}

\section{Keywords}

Corneal Limbal Dermoid, Amniotic Membrane Graft, Choriostoma

\section{Introduction}

Corneal dermoids, most often found in the inferior temporal limbus, are choristomas with ectodermal and mesodermal origins that contain keratinized squamous epithelium, hair follicles and other appendages. They are a major cosmetic problem in addition to causing astigmatism, anisometropia, dry eye, and amblyopia [1]-[3]. Epibulbar dermoids are among the most common benign pediatric tumors [4] and are classified into three different classes; class I dermoids are $<5 \mathrm{~mm}$ and are localized to the limbus; class II dermoids extend beyond the cornea stroma, stretching down to the Descemet's membrane without involving it; class III dermoids cover the whole cornea and invade the anterior chamber of the eye [5] [6]. They have a variant pattern of inheritance with 
occasional systemic findings. Some studies have noted that dermoid choriostomas present alongside other ocular findings such as scleral/corneal staphyloma, aniridia, congenital aphakia, cataract, and microphthalmia [7]. Differential diagnosis of corneal limbal dermoids includes squamous cell carcinoma and epithelial epithelioma, both of which are usually located at the corneal limbus. Goldenhars syndrome, oculo-auriculovertebral dysplasia, will often present with limbal dermoids. Other associated signs of Goldenhars Syndrome include preauricular skin appendages, mandibular hypoplasia and vertebral malformations such as scoliosis and spina bifida [8].

Different factors are considered in the clinical decision to excise grade II limbal dermoids. Indications for surgery include: induction of irregular astigmatism, presence of amblyopia or clinically-significant anisometropia, progressive dellen, ocular discomfort, noncompliance with amblyopia or other medically-necessary therapy, psychosocial concerns, rate of growth, and exposure keratopathy due to inability to close the eyelids. There are many different opinions about the optimal method and appropriate time for removal of these tumors [5]. Obtaining a thorough history, serial monitoring of the dermoid during office visits using cycloplegic retinoscope to measure the dermoid's size, assessment for change in amblyopia, and the use of ultrasound biomicroscopy to assess the involvement of Descemet's membrane play a big role in the choice of what surgical technique to use [9]-[11]. Authors have found optical coherence tomography (OCT) helpful in determining the depth of the dermoid involvement in cornea. Techniques used in the past include simple superficial keratectomy, lamellar keratoplasty, penetrating keratoplasty, simple excision plus the use of circumlimbal pericardial grafts, fibrin glue-assisted amniotic membrane graft. Excision plus corneal tattooing using sutureless limbo-conjuctival autograft was recently described [6]. This case presentation describes reconstruction using amniotic membrane graft with fibrinogenthrombin glue plus sutures.

\section{Case}

The patient's legal guardian provided written consent for the publication of personal information, including medical record details and photographs.

A five year old was referred to our clinic for further evaluation of his right eye for a 5 $\times 5 \mathrm{~mm}$ corneal limbal dermoid with eye lashes growing on it (Figure 1). The dermoid had been present since birth. Mom stated that the dermoid grew larger gradually over 2 to 3 years and caused the patient irritation leading to constant rubbing of his eye. His ocular history was significant for amblyopia in the right eye for which he had been wearing an eye patch, anisometropia and bilateral hyperopia with astigmatism. No other systemic medical history was reported.

On his initial pre-operative exam, mild ptosis was noted in the right eye, and the fundoscopic exam was within normal limits with no signs of optic nerve edema. The slit lamp exam was unremarkable except for the $5 \times 5 \mathrm{~mm}$ corneal limbal dermoid that was raised with approximately 30 lashes growing on the surface. The dermoid extended approximately $3 \mathrm{~mm}$ onto the cornea with corneal stroma involvement posteriorly. There 


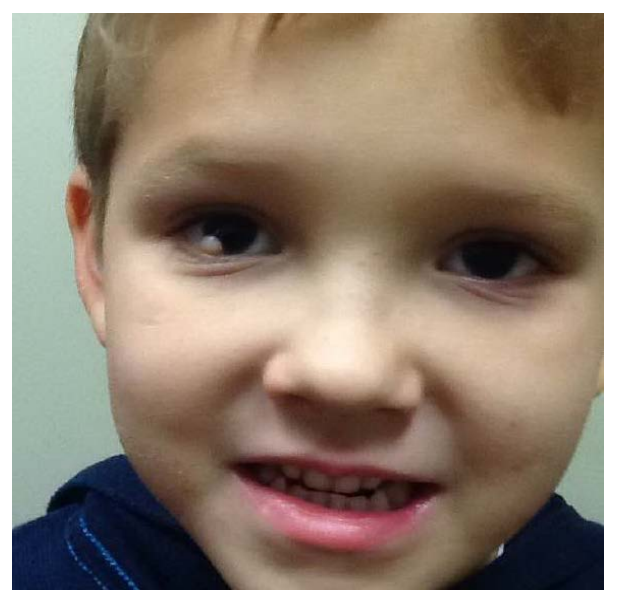

Figure 1. Corneal limbal dermoid of the right eye.

were mild punctate epithelial erosions on the cornea surrounding the dermoid. Visual acuity using Lea Symbols was 20/50 with intraocular pressures of $12 \mathrm{mmHg}$ for the right eye and 20/20 with pressures of $10 \mathrm{mmHg}$ for the left eye; visual fields were full in both eyes. The cycloplegic refraction test showed a sphere of $+3.50-1.50 \times 045$ for the right eye and a sphere of $+2.00-2.00 \times 180$, for the left eye. On retinoscopy, there was a significant irregularity of the reflex on the right eye. The parents were given the option to observe or surgically excise the dermoid. The decision was made to excise due to discoloration of the cornea, increase in size of the dermoid, and irritation to the patient.

Surgical technique: Right eye was prepped and draped in sterile fashion. 4.0 silk was placed superiorly for traction and pulled superiorly to expose the corneal dermoid mass with eyelashes growing on the surface. The corneal dermoid mass was carefully removed using a crescent blade. Care was taken to avoid any perforation of the cornea. Cautery was used to obtain hemostasis and a diamond burr was used to smooth the surface of the cornea after the excision. The corneal and conjunctival mass was also removed and a specimen was sent to the lab. After surgery, the area of the involved cornea was approximately 50 percent thinner than the rest of the cornea. Cryopreserved human amniotic membrane was used to close the defect of the conjunctiva and cornea. Tisseel glue (a combination of fibrinogen and thrombin) was used along with 4 interrupted sutures using a 9.0 vicryl. Tobradex ointment was placed on the eye. A pressure patch was placed along with a Fox eye shield for 1 day then was removed on post operative day one.

The sample was described histologically as a portion of squamous epithelium lined with fibrovascular tissue with adnexal structures and a focal squamous epithelium lined cystic space consistent with corneal dermoid (Figure 2).

Follow up: One day after the surgery, there were no signs of infection at the incision site, no exudates or wound dehiscence. There was some slight residual opacity at the inferotemporal quadrant (Figures 3(a)-(c)). Visual acuity using Lea Symbols was 20/50 with intraocular pressures of 16 for the right eye.

Nine days postoperatively, patient denied any complains of pain, and there were no 


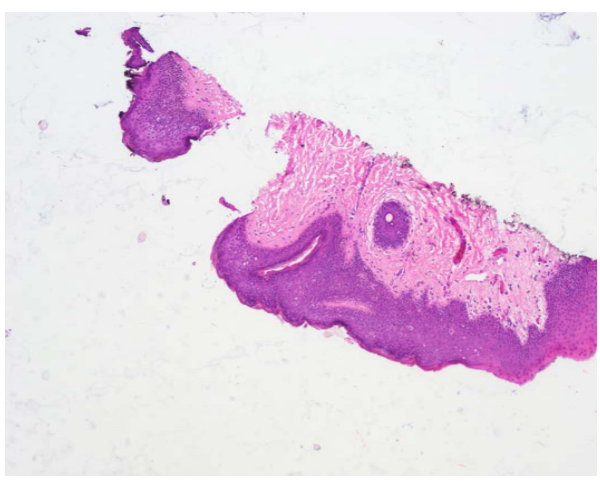

(a)

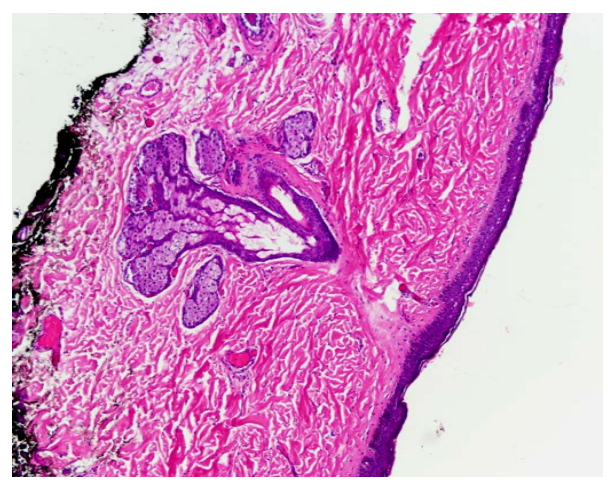

(b)

Figure 2. Histological slides representing squamous epithelium lined cystic space.

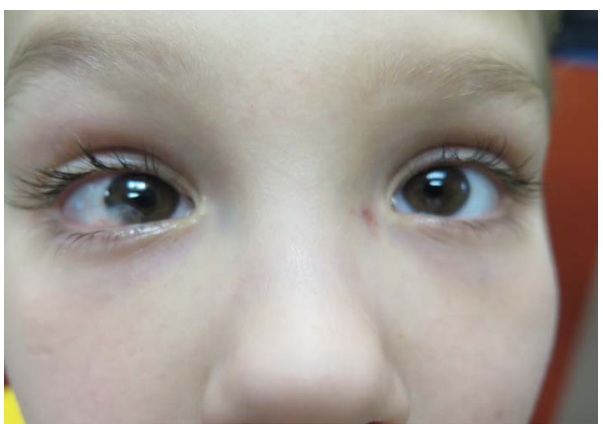

(a)

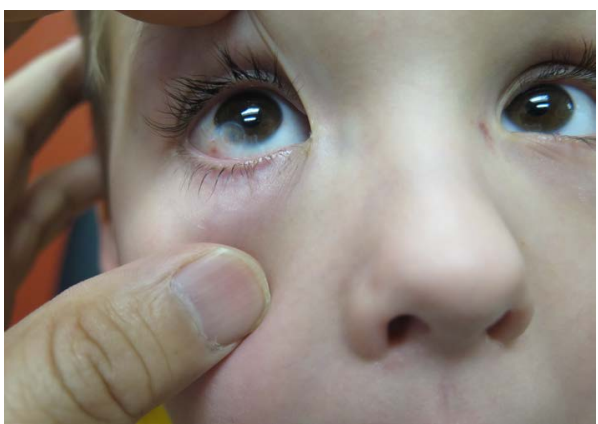

(b)

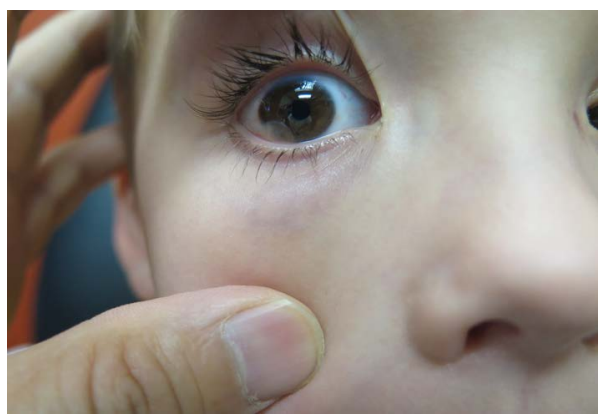

(c)

Figure 3. Status-post surgical excision with slight residual opacity of the inferotemporal quadrant.

signs of infection, no exudates, or wound dehiscence. Visual acuity slightly improved to $20 / 40$ but astigmatism remained. The pictures below depict the right eye one month after the surgery.

\section{Discussion}

The amniotic membrane is a derivative of the fetal ectoderm that makes up the innermost layer of the fetal membrane. It was first used as a substitute for rabbit peritoneum [12] in the management of ocular chemical burns and now has a varied amount of uses, including its use in recurrent corneal erosion and severe dry eye. Amniotic membranes 
are being used as grafts due to their ability to reduce postoperative pain, corneal neovascularization and inflammation that leads to scarring due to its in-vitro inhibition of TGF B [13]. They also promote epithelialization and differentiation of ocular epithelium by protection of limbal stem cells [14]. For these reasons, we used the amniotic membrane as our graft of choice. Extra caution was taken in our case by using a fibrinogen plus thrombin glue which forms a smooth seal along the wound edge and dissolvable 9.0-vicryl sutures to ensure proper placement and fixation of the amniotic graft in this pediatric patient. By using dissolvable sutures, we eliminated the need for suture removals in the future.

Other cases of limbal dermoids with corneal surface lashes have been reported although different approaches were used for reconstructive purposes. Mahdavi and Pourafkari reported a case of a 19-year-old man with a limbal dermoid cyst measuring 5 $\mathrm{mm}$ by $6 \mathrm{~mm}$ with black hair. The lesion was excised, and lamellar keratoplasty performed. They saw minimal improvement in visual acuity after surgery as a result of the amblyopia and induced astigmatism [15]. Pirouzian et al. reported a case of three limbal dermoid patients who underwent deep lamellar excision followed by sutureless multilayered amniotic membrane transplantation and reported improved cosmetic outcomes [16]. Jeong et al. excised 4 limbaldermoids in 4 patients and used a combination of simple excision, corneal tattooing, and a sutureless limboconjunctival autograft. They also report satisfactory cosmetic outcomes [3]. Lazzaro describes the excision of a limbal dermoid with the placement of a processed pericardial graft and stated beneficial results for larger lesions [17].

Complications after surgery may include potential risk of scarring, loss of vision, and development of pseudopterygium. However, use of amniotic membrane may reduce the regrowth of the dermoid needing repeat surgeries in our experience. Lang et al. purported that the transplantation of amniotic membrane following removal of a limbal dermoid could not prevent the occurrence of a pseudopterygium but the use of Mitomycin C had a protective effect. They hypothesize that Mitomycin C inhibits fibroblast growth and consequently the occurrence of a pseudopterygium or corneal neovascularization [18]. Our patient did not develop these complications after the procedure although mitomycin C was not used. Also, the use of Mitomycin C in pediatric patients in corneal surgeries still remains controversial.

Although vision improved slightly, we did not notice a significant change in astigmatism or anisometropia with our patient, consistent with other studies [5].

With the current amount of knowledge of excision of limbaldermoids and reconstruction using different techniques, many clinicians have reported minimal or no changes in vision or astigmatism and no change in the degree of amblyopia. Using the amniotic membrane after excision of the dermoid is a relatively new technique. A combination of the amniotic membrane and use of the thrombin/fibrinogen glue gave us a slight improvement in vision not seen with some techniques but the degree of astigmatism remained unchanged. More work needs to be done to develop a technique that improves the degree of astigmatism after excision of limbaldermoids but we propose 
that surgery should be considered over medical management in a case of persistant discomfort, disfigurement, visual changes and an enlarging cyst.

\section{Conclusion}

Our case presentation adds to the number of reported limbal dermoids with corneal surface lashes. Surgically removing the limbal dermoid was successful and led to a good outcome with symptomatic relief of constant irritation. Different methods have been used in reconstruction after excision. In our case, using the fibrinogen plus thrombin glue and sutures after amniotic membrane graft transplant did not change the degree of astigmatism or anisometropia, but there was a slight improvement in vision. Surgery may be considered for irritation due to lash growth, discomfort, appearance of disfigurement, and an enlarging cyst. However, it may not reduce the degree of astigmatism or grossly improve vision.

\section{References}

[1] Basic Clinical and Science Course. Pediatric Ophthalmology and Strabismus. 2013-14. Section 6, 343-344.

[2] Basic Clinical and Science Course. Orbit, Eyelids, and Lacrimal System. 2013-14. Section 7, 36-37.

[3] Grossniklaus, H.E., Green, W.R., Lukenbach, M., et al. (1987) Conjunctival Lesions in Adults: A Clinical and Histopathological Review. Cornea, 6, 78-116. http://dx.doi.org/10.1097/00003226-198706020-00002

[4] Harminder, D., Jose, G., Anthony, K. and Maharajan, V. (2004) The Amniotic Membrane in Ophthalmology. Survey of Ophthalmology, 49, 51-77. http://dx.doi.org/10.1016/j.survophthal.2003.10.004

[5] Hoops, J.P., Ludwig, K., Boergen, K.P. and Kampik, A. (2001) Preoperative Evaluation of Limbal Dermoids Using High-Resolution Biomicroscopy. Graefe's Archive for Clinical and Experimental Ophthalmology, 239, 459-461. http://dx.doi.org/10.1007/s004170100300

[6] Jeong, J., Song, Y.J., Jung, S.I. and Kwon, J.W. (2015) New Surgical Approach for Limbal Dermoids in Children: Simple Excision, Corneal Tattooing, and Sutureless Limboconjunctival Autograft. Cornea, 34, 720-723. http://dx.doi.org/10.1097/ICO.0000000000000440

[7] Lang, S.J., Böhringer, D. and Reinhard, T. (2014) Surgical Management of Corneal Limbal Dermoids: Retrospective Study of Different Techniques and Use of Mitomycin C. Eye, 28, 857-862. http://dx.doi.org/10.1038/eye.2014.112

[8] Lanzl, I.M., Augsburger, J.J., Hertle, R.W., Rapuano, C., Correa-Melling, Z. and Santa Cruz, C. (1998) The Role of Ultrasound Biomicroscopy in Surgical Planning for Limbal Dermoids. Cornea, 17, 604-606. http://dx.doi.org/10.1097/00003226-199811000-00006

[9] Lee, S.B., Li, D.Q., Tan, D.T., Meller, D.C. and Tseng, S.C. (2000) Suppression of TGF-Beta Signaling in Both Normal Conjunctival Fibroblasts and Pterygial Body Fibroblasts by Amniotic Membrane. Current Eye Research, 20, 325-334. http://dx.doi.org/10.1076/0271-3683(200004)2041-5FT325

[10] Meller, D., et al. (2011) Amniotic Membrane Transplantation in the Human Eye. Deutsches Ärzteblatt International, 108, 243-248.

[11] Pirouzian, A., et al. (2011) Fibrin-Glue Assisted Multilayered Amniotic Membrane Transplantation in Surgical Management of Pediatric Corneal Limbal Dermoid: A Novel Ap- 
proach. Graefe's Archive for Clinical and Experimental Ophthalmology, 249, 261-265. http://dx.doi.org/10.1007/s00417-010-1499-2

[12] Pirouzian, A. (2013) Management of Pediatric Corneal Limbal Dermoids. Clinical Ophthalmology (Auckland, N.Z.), 7, 607-614. http://dx.doi.org/10.2147/OPTH.S38663

[13] Robb, R.M. (1996) Astigmatic Refractive Errors Associated with Limbal Dermoids. Journal of Pediatric Ophthalmology \& Strabismus, 33, 241-243.

[14] Sunderraj, P.P., Viswanathan, R.K. and Balachander, R. (1991) Neoplasms of the Limbus. Indian Journal of Ophthalmology, 39, 168-169.

[15] Fard, A.M. and Pourafkari, L. (2013) The Hairy Eyeball. New England Journal of Medicine, 368, 64. http://dx.doi.org/10.1056/NEJMicm1208993

[16] Pirouzian, A., Holz, H., Merrill, K., Sudesh, R. and Karlen, K. (2012) Surgical Management of Pediatric Limbaldermoids with Sutureless Amniotic Membrane Transplantation and Augmentation. Journal of Pediatric Ophthalmology \& Strabismus, 49, 114-119. http://dx.doi.org/10.3928/01913913-20110823-01

[17] Lazzaro, D.R. and Coe, R. (2010) Repair of Limbal Dermoid with Excision and Placement of a Circumlimbal Pericardial Graft. Eye \& Contact Lens, 36, 228-229. http://dx.doi.org/10.1097/ICL.0b013e3181e465bf

[18] Shields, J.A. and Shields, C.L. (2004) Orbital Cysts of Childhood Classification, Clinical Features and Management. Survey of Ophthalmology, 49, 281-299.

http://dx.doi.org/10.1016/j.survophthal.2004.02.001

\section{Submit or recommend next manuscript to SCIRP and we will provide best service} for you:

Accepting pre-submission inquiries through Email, Facebook, LinkedIn, Twitter, etc. A wide selection of journals (inclusive of 9 subjects, more than 200 journals)

Providing 24-hour high-quality service

User-friendly online submission system

Fair and swift peer-review system

Efficient typesetting and proofreading procedure

Display of the result of downloads and visits, as well as the number of cited articles

Maximum dissemination of your research work

Submit your manuscript at: http://papersubmission.scirp.org/

Or contact ojoph@scirp.org 